\title{
Dentin Biomodification Agents in Dentistry-A Critical Review
}

\section{Bárbara de Fátima Barboza de Freitas, Antônio Moisés Parente da Ponte, Fabrício Rômulo Sampaio Farias, Victor Pinheiro Feitosa, Diego Martins de Paula}

\author{
Paulo Picanço School of Dentistry, Fortaleza, Brazil
}

\begin{abstract}
Objective: To carry out a literature review on the dentin biomodification agents used in dental research.

Methods: The PubMed database and collected literature were used as a resource for peer-reviewed articles to highlight the topics of dentin hierarchical structure, biomodification agents, and investigations of their laboratory and clinical applications.

Results: Biomodification agents can be categorized as physical methods and chemical agents. Synthetic and naturally occurring chemical strategies present a distinctive mechanism of interaction with the tissue. Initially thought to be driven only by inter-or intra-molecular collagen-induced non-enzymatic collagen cross-linking, multiple interactions with other dentin components are fundamental for the long-term biomechanics and biostability of the tissue.

Conclusion: Riboflavin is a physical agent that is difficult to obtain in industrial terms compared to natural extracts from plants such as proanthocyanidin that can be extracted from natural sources. Cardol and cardanol are industrial discard products and are a good choice for every day being produced on a large scale. Curcumin and chitosan have more accessibility in the extraction. Those of synthetic origin, such as glutaraldehyde have cytotoxic potential and carbodiimide has been a favorable substitute due to lower cytotoxic potential.
\end{abstract}

Key Words: Proanthocyanidin, Glutaral, Ethyldimethylaminopropyl carbodiimide, Anacardium, Riboflavin, Cross-linking reagents

\section{Introduction}

The structural complexity of dentin is the major challenge for the longevity of composite resin restorations. The dentin is composed of mainly fibrillar collagen type I that provides tissue resistance, and cohesion reinforced by the formation of cross-links, which increase the fibrillar resistance against degradation, as well as provides good properties mechanical [1]. Other non-collagenous proteins such as proteoglycans, for the most part, endogenous proteases, such as Matrix Metalloproteinases (MMPs) and cysteine-cathepsins [2,3] are present in dentin tissue.

The current restorative procedures often depend on substantially the infiltration of synthetic polymers of the adhesive system into partially or totally demineralized collagen fibers that make up the dentin organic matrix [4]. This combination of dentin-polymer is called the hybrid layer [5].

Several factors have been attributed to the reduction of bond strength and degradation of the hybrid layer, such as excess hydrophilic monomers incorporated in the adhesive systems, the high water concentration in the bonding procedure, inadequate infiltration of the monomers into the demineralized collagens, among others [6]. The presence of water in the hybrid layer leads to the hydrolysis of monomers and unprotected collagen fibers [7-9].

Non-infiltrated and exposed collagenous lesions are also targets of endogenous proteases such as MMPs (2, 3, 8, 9 and 20) and cathepsins [10]. Therefore, the use of strategies such as the biomodification of dentin and the application of inhibitors of MMPs and cathepsins to improve the mechanical properties of the bonding interface as the reinforcement of substrate properties has been increasingly highlighted and are important resources in the attempt to extend the bonding longevity between dentin and resin [11]. Much money is currently spent replacing composite resin restorations, which last around 5 to 8 years $[12,13]$.

This new approach to restorative dentistry uses synthetic biomodification agent or natural products that $[8,14]$, increase the potential for cross-linking between the collagen fibers to improve the biomechanical and reduce biodegradation [8]. Despite being an innovative technique, dentinal biomodification is little known by dentists. Thus, it would be interesting to present a literature review encompassing the most promising techniques and products in order to improve the stability of restorations with minimal cytotoxic effects.

The present study aims to perform a literature review about the dentin biomodification agents used in dentistry.

Table 1. Summary table of the main biomodifiers used in dentistry.

\begin{tabular}{|l|l|}
\hline Types of biomodification & Biomodifiers \\
\hline Physical Methods & Riboflavin with ultraviolet radiation \\
\hline Chemical agents & Glutaraldehyde \\
\cline { 2 - 2 } Synthetics & Carbodiimide \\
\cline { 2 - 2 } & Chitosan \\
\cline { 2 - 2 } & Curcumin \\
\hline \multirow{5}{*}{ Naturals } & Proanthocyanidin \\
\cline { 2 - 2 } & Cardol and Cardanol \\
\cline { 2 - 2 } & Epigallocatechin 3-gallate \\
\cline { 2 - 2 } & Extract of the aroeira \\
\hline
\end{tabular}

\section{Critical Review of the Literature}

Collagen cross-linking agents by physical methods or by chemical agents have been proposed as adjuvants in 
restorative procedures to increase the structural stability of dentin collagen by the addition of inter- and intramolecular bonds and to increase the durability of resin-dentin attachment [15]. Table 1 summarizes the main types of biomodification agents used in dentistry and will be addressed in this review.

\section{Physical Methods}

Riboflavin (RF), 7,8-dimethyl-10-ribitylisoalloxazine, is a water-soluble vitamin belonging to the vitamin B 2 complex. It has been used in conjunction with ultraviolet A UVA irradiation in experimental restorative dentistry as a biomodification agent) $[8,15]$.

The high energy UVA light (365 nm wavelength) breaks down the intrinsic bonds of collagen and generates oxygen free radicals. Hydroxyl functional clusters in RF attack proline or lysine in the collagen. In addition, RF acts as a photosensitizer for UVA, promoting the formation of new cross-links [15]. The use of RF/UVA increased resistance to collagen degradation mediated by collagenase, in addition to significant improvement in tensile strength [16].

The isolated use of UVA has already shown a biomotifier effect, reducing the degradation of dentin, but associated with RF showed better effectiveness against collagenases [17]. An alternative to UVA light is the visible blue light that has already been tested and has proved to be a promising substitute since it is clinically more applicable and acceptable within the dentistry clinic [17].

\section{Chemical Agents}

Chemical biomodification agents may be synthetic or natural substances.

\section{Synthetics}

Aldehydes have been applied to this for some time [18]. Glutaraldehyde (GA) and carbodiimide (EDC) are well known. The GA has the ability to cross-link with the amino groups of the collagen Lysine and Hydroxylisine, demonstrating an increase in tensile strength and elasticity and with the ability to reduce degradation [19]. However, its cytotoxic effect limits its use in dentistry [10]. EDC has been used as a cross-linking agent as an alternative to glutaraldehyde, with lower cytotoxic potential [20,21]. Its potential is non-specific by the activation of the carboxylic acid groupings of glutamic and aspartic acids to form an Oacylsourea intermediate. After, reacts with the amino groups of lysine and hydroxylysine to form an amide. However, there is a need for 1 to 4 hours of application to activity, clinically unacceptable [19].

There are specific inhibitors of MMP's, such as galardin and clorexidine. The galardin is a synthetic inhibitor of MMP with potent against MMP's 1, 2, 3, 8 and 9. Its mechanism of action is based on the chelation of the zinc ions located in the catalytic domain of MMPs [14]. In the work of, the treatment with galardin delayed the decline bond strength in addition to the amount of nanoinfiltration, but did not completely block these phenomena, being an inhibitor of dentin MMPs and it may be a clinically relevant way to increase the longevity of the restorations by the protection of the hybrid layer.
Chlorhexidine can be used to inhibit MMPs 2, 8, 9, without having a cytotoxic effect [22]. Even at low concentrations $(0.2 \%)$, chlorhexidine showed preservation of bond strength and reduced interface degradation, expressed by the reduction of nanoinfiltration. The inhibition mechanism of chlorhexidine occurs by inhibition of proteases because of its chelating property with calcium ions [14,22]. The major problem with chlorhexidine is its low substantivity when applied in dentin [23].

\section{Natural}

The use of natural agents from plants has been a major attractive by the presence of polyphenols found in its composition that demonstrate very effective action in relation to cross-links of collagen and not have cytotoxic effects.

Proanthocyanidins (PAC) are derived from plants and are been studied for more than 15 years in dentistry [24]. They have a high structural diversity based on four molecules (catechin, ent-catechin, epicatechin, epicatechin), different types of interflavonoid bonds, and several chain lengths, known as the degree of polymerization [25]. Some sources of PACs have already been tested such as cocoa seed (Theobroma cacao), tea plant leaves (Camellia sinensis), cinnamon bark stem (Cinnamon Verum), açaí fruit (Euterpe precatory) and bark of the pine tree (Pinus massoniana). The one that showed better results in dentin was that of the grape seed (Vitisvinifera) [3,26].

The application of PACs in human dentin mimics different levels cross-linking of collagen by non-enzymatic interactions resulting in improved biomechanics and biostability [21]. In addition, they increase the tensile strength properties [27] resistance to biodegradation [28] and the module of elasticity [29]. The ability to connect in proline-rich proteins favors immediate adhesion and stabilization and to collagen fibers, ever in demineralized dentin [25]. Liu et al. [30] showed that both the activity collagenolytic and gelatinolytic in the demineralized dentin are notably inhibited by PAC-modulated dentin biomodification.

Cardol and cardanol, derived from the liquid cashew nut (LCC, Anacardiumoccidentale), have already been tested to evaluate the mechanical properties of dentin [31] and as a dentin desensitizer [32]. Its chemical structures are phenols, which are capable of cross-links through hydrogen bonds chain responsible for a hydrophobic characteristic.

The main polyphenol found in green tea (Camellia sinensis) and inhibitor of MMP (2 and 9) is epigallocatechin 3-gallate (EGCG). Beyond the ability to cross-link, still has an antimicrobial potential against Gram-positive and Gramnegative bacteria [33]. The application of $0.1 \%$ EGCG as a dentin pretreatment associated with an adhesive conventional 2 -step design resulted in the maintenance of the bond strength after 6 months of water storage [34].

The aroeira extract (Myracrodruon urundeuva), is an antiinflammatory agent and antimicrobial. When tested in dentin showed improvements in properties mechanical properties of dentin and degradation [31].

Curcumin is a naturally occurring pigment that is part of an active component of dentin-tested saffron, which showed 
reduce MMP activity in pre-treated samples with biomodification agents [35], also confirmed a decrease in gelatinolytic activity and in the amount of total protein extractable and showed a reduction in the release of MMP-8, MMP-2 and MMP-9 [35]. In addition, curcumin yielded lower dry mass loss in relation to other biomodification agents and showed perfect action against degradation of collagen mediated by cathepsin K [36]. Also, another study aimed to evaluate the inactivation effect of several proteases from dentin over a period of 6 months, where curcumin was very effective, maintained its inhibitory effect during 6 months of incubation. The results were confirmed by the loss of dry mass and relative activity of MMP.

Chitosan is a cationic polysaccharide produced through the deacetylation of chitin, a polysaccharide found in the exoskeleton of crustaceans, through an alkalinization process under high temperatures. The application of chitosan has been a new study in the experimental restorative dentistry as a biomedical agent. Chitosan showed a significant increase in the resistance to degradation of collagenase after dentin ocolagene is coated with nanoparticles of chitosan (CSnp). It also showed increase the microhardness of the root dentin layer [37], in addition, the chitosan modified with methacrylate is proposed as a component of an etch-and-rinse adhesive, a system to improve the durability of dental restorations [38]. In addition, the use of chitosan/riboflavin to modify collagen dentine, with the defined proportions, stabilizes the fibrillar network of collagen enhances resin infiltration and hybrid layer formation [39].

\section{Conclusion}

\section{Final Thoughts and Future Trends}

By means of the aforementioned, the origin of each product contributes greatly to its use, the way of application and the ease of clinical use. Riboflavin is a physical agent that is difficult to obtain in industrial terms compared to natural extracts from plants such as proanthocyanidin that can be extracted from tea leaves (Camellia sinensis), cinnamon bark (Cinnamon verum), açaí fruit (Euterpe precatoria) and pine bark (Pinus massoniana), grape seed (Vitis vinifera) showing itself more easily accessible to the market. Cardol and cardanol, derived from cashew nuts (LCC, Anacardium occidentale), are industrial waste and are a good choice for every day being produced on a large scale, improvements in the aspect of Dentistry and the sustainability of the environment. In addition to curcumin and chitosan, curcumin has more accessibility in the extraction with regard to chitosan that is extracted through of chitin deacetylation, a polysaccharide found the exoskeleton of crustaceans, which is extracted through a process alkalinization under high temperatures. Those of synthetic origin, such as glutaraldehyde have cytotoxic potential and carbodiimide has been a favorable substitute for having a lower cytotoxic potential.

\section{References}

1. Bedran Russo AK, Pashley DH, Agee K, Drummond JL, Miescke KJ. Changes in stiffness of demineralized dentin following application of collagen crosslinkers. Journal of Biomedical Materials Research Part B: Applied Biomaterials. 2008; 86: 330-334.

2. Goldberg M, Kulkarni AB, Young M, Boskey A. Dentin: structure, composition and mineralization: the role of dentin ecm in dentin formation and mineralization. Frontiers in Bioscience: $A$ Virtual Library of Medicine. 2011; 1: 711-735.

3. Aguiar TR, Vidal CMP, Phansalkar RS, Todorova I, Napolitano JG, et al. Dentin biomodification potential depends on polyphenol source. Journal of Dental Research. 2014; 93: 417-422.

4. Niu LN, Zhang W, Pashley DH, Breschi L, Mao J, et al. Biomimetic remineralization of dentin. Dental Materials. 2014; 30: 77-96.

5. Nakabayashi N, Kojima K, Masuhara E. The promotion of adhesion by the infiltration of monomers into tooth substrates. Journal of Biomedical Materials Research. 1982; 16: 265-273.

6. Singh P, Nagpal R, Singh UP, Manuja N. Effect of carbodiimide on the structural stability of resin/dentin interface. Journal of Conservative Dentistry. 201; 19: 501-509.

7. Breschi L, Mazzoni A, Ruggeri A, Cadenaro M, Lenarda RD, et al. Dental adhesion review: Aging and stability of the bonded interface. Dental Materials. 2008; 24: 90-101.

8. Bedran Russo AK, Pauli GF, Chen S, Mcalpine J, Castellan $\mathrm{CS}$, et al. Dentin biomodification: strategies, renewable resources and clinical applications. Dental Materials. 2014; 30: 62-76.

9. Vidal CMP, Aguiar TR, Phansalkar R, McAlpine JB, NapolitanoJG, et al. Galloyl moieties enhance the dentinbiomodification potential of plant-derived catechins. Acta Biomaterialia. 2014; 10: 3288-3294.

10. Pashley DH, Tay FR, Breschi L, Tjäderhane L, Carvalho RM, et al. State of the art etch-and-rinse adhesives. Dental Materials. 2011; 27: 1-16.

11. Tay FR, Pashley DH. Biomimetic remineralization of resinbonded acid-etched dentin. Journal of Dental Research. 2009; 88: 719-724.

12. Bertassoni LE, Orgel JP, Antipova O, Swain MV. The dentin organic matrix-limitations of restorative dentistry hidden on the nanometer scale. Acta Biomaterialia. 2012; 8: 2419-2433.

13. Nam JW, Phansalkar RS, Lankin DC, McAlpine JB, LemeKraus AA, et al. Absolute configuration of native oligomeric proanthocyanidins with dentin biomodification potency. The Journal of Organic Chemistry. 2017; 82: 1316-1329.

14. Breschi L, Martin P, Mazzoni A, Nato F, Carrilho M, et al. Use of a specific MMP-inhibitor (galardin) for preservation of hybrid layer. Dental Material. Copenhagen. 2010; 26: 571-578.

15. Chiang YS, Chen YL, Chuang SF, Wu CM, Wei PJ, et al. Riboflavin-ultraviolet-A-induced collagen cross-linking treatments in improving dentin bonding. Dental Material. 2013; 29: 682-692.

16. Fawzy A, Nitisusanta L, Iqbal K, Daood U, Beng LT, et al. Characterization of riboflavin-modified dentin collagen matrix. Journal of Dental Research. 2012; 91: 1049-1054.

17. Seseogullari Dirihan R, Tjäderhane L, Pashley DH, Tezvergil Mutluay A. Effect of ultraviolet A-induced cross linking on dentin collagen matrix. Dental Material. 2015; 31: 1225-1231.

18. Xu C, Wang Y. Cross-linked demineralized dentin maintains its mechanical stability when challenged by bacterial collagenase. Journal of Biomedical Materials Research Part B: Applied Biomaterials. 2011; 96: 242-248.

19. Tezvergil Mutluay A, Mutluay MM, Agee KA, Seseogullari Dirihan R, Hoshika T, et al. Carbodiimide cross-linking inactivates soluble and matrix-bound MMPs, in vitro. Journal of Dental Research. 2012; 91: 192-196.

20. Bedran Russo AK, Vidal CM, Dos Santos PH, Castellan CS. Long-term effect of carbodiimide on dentin matrix and resin-dentin bonds. Journal of Biomedical Materials Research Part B: Applied Biomaterials. 2010; 94: 250-255.

21. Cristina MP Vidal, Weiying Zhu, Suresh Manohar, Berdan Aydin, Timothy A. Keiderling, et al. Collagen-collagen interactions mediated by plant-derived proanthocyanidins: A spectroscopic and 
atomic force microscopy study. Acta Biomaterialia. 2016; 41: $110-118$.

22. Mazzoni A, Tjäderhane L, Checchi V, Di Lenarda R, Salo T, et al. Role of dentin MMPs in caries progression and bond stability. Journal of Dental Research. 2015; 94: 241-251.

23. Loguercio AD, Stanislawczuk R, Polli LG, Costa JA, Michel $\mathrm{MD}$, et al. Influence of chlorhexidine digluconate concentration and application time on resin-dentin bond strength durability. European Journal of Oral Sciences. 2009; 117: 587-596.

24. Han B, Jaurequi J, Tang BW, Nimni ME. Proanthocyanidin: a natural crosslinking reagent for stabilizing collagen matrices. Journal of Biomedical Materials Research Part A. 2003; 65: 118-124.

25. Castellan CS, Bedran Russo AK, Antunes A, Pereira PN. Effect of dentin biomodification using naturally derived collagen cross-linkers: one-year bond strength study. International Journal of Dentistry. 2013.

26. Castellan CS, Bedran Russo AK, Karol S, Pereira PN. Longterm stability of dentin matrix following treatment with various natural collagen cross-linkers. Journal of the Mechanical Behavior of Biomedical Materials. 2011; 4: 1343-1350.

27. Bedran Russo AK, Castellan CS, Shinohara MS, Hassan L, Antunes A. Characterization of biomodified dentin matrices for potential preventive and reparative therapies. Acta Biomaterialia. 2011; 7: 1731-1741.

28. Liu Y, Chen M, Yao X, Xu C, Zhang Y, et al. Enhancement in dentin collagen's biological stability after proanthocyanidins treatment in clinically relevant time periods. Dental Material. 2013; 29: 485-492.

29. Castellan CS, Pereira PN, Viana G, Chen SN, Pauli GF, et al. Solubility study of phytochemical cross-linking agents on dentin stiffness. British Dental Journal. 2010; 38 : 431-436.

30. Liu RR, Fang M, Zhang L, Tang CF, Dou Q, et al. Antiproteolytic capacity and bonding durability of proanthocyanidinbiomodified 31 demineralized dentin matrix. International Journal of Oral Science. 2014; 6 : 168-174.
31. Moreira MA, Souza NO, Sousa RS, Freitas DQ, Lemos MV, et al. Efficacy of new natural biomodification agents from Anacardiaceae extracts on dentin collagen cross-linking. Dental Materials. 2017; 33: 1103-1109.

32. Moreira MM, Da Silva LRR, Mendes TAD, Santiago SL, Mazzetto SE, et al. Synthesis and characterization of a new methacrylate monomer derived from the Cashew Nut Shell Liquid (CNSL) and its effect on dentinal tubular occlusion. Dental Materials. 2018; 34: 1144-1153.

33. De Macedo FAA, Souza NO, Lemos MVS, De-Paula DM, Santiago SL, et al. Dentin bonding and physicochemical properties of adhesives incorporated with epigallocatechin-3-gallate. Odontology. 2019; 107: 23-28.

34. Santiago SL, Osorio R, Neri JR, Carvalho RM, Toledano M. Effect of the flavonoid epigallocatechin-3-gallate on resin-dentin bond strength. The Journal of Adhesive Dentistry. 2013; 15: 535-540.

35. Seseogullari Dirihan R, Apollonio F, Mazzoni A, Tjaderhane $\mathrm{L}$, Pashley D, et al. Use of crosslinkers to inactivate dentin MMPs. Dental Materials. 2016; 32: 423-432.

36. Seseogullari Dirihan R, Mutluay MM, Vallittu P, Pashley DH, Tezvergil-Mutluay A. Effect of pretreatment with collagen crosslinkers on dentin protease activity. Dental Materials. 2015; 31: 941-947.

37. Nikhil V, Jaiswal S, Bansal P, Arora R, Raj S, et al. Effect of phytic acid, ethylenediaminetetraacetic acid, and chitosan solutions on microhardness of the human radicular dentin. Journal of Conservative Dentistry. 2016; 19: 179-183.

38. M Diolosà I, Donati G Turco, M Cadenaro R. Di Lenarda, L Breschi, S Paoletti. Use of methacrylate-modified chitosan to increase the durability of dentine bonding systems. Biomacromolecules. 2014; 15: 4606-4613.

39. Daood U, Iqbal K, Nitisusanta LI, Fawzy AS. Effect of chitosan/riboflavin modification on resin/dentin interface: spectroscopic and microscopic investigations. Journal of Biomedical Materials Research Part A. 2013; 101: 1846-1856. 